\title{
O COMPORTAMENTO DA CAUSA PETENDI NOS RECURSOS DE ESTRITO DIREITO - BREVE OBSERVAÇÃO
}

\author{
MENDONÇA, João Josué Walmor de $\mathrm{e}^{33}$
}

Recebido em: 2008-07-11

Aprovado em: $2008-08-28$

ISSUE DOI: $10.3738 / 1982.2278 .113$

RESUMO: A causa de pedir (causa petendi) no ordenamento jurídico pátrio é fundamental na identificação da demanda e da pretensão do direito de ação do autor desta. Gravita essa causa de pedir em duas correntes doutrinárias que procuram dar relevo no elemento ao qual pugna por ser prevalente em detrimento do outro. Ao observar este instituto processual, aqui, nos recursos de estrito direito, a característica e natureza própria desses recursos, modificam a concepção ordinária do objeto observado, a inverter a substância deste, mas não a sua essencialidade. Restringe-se, por tudo, este estudo, à causa de pedir um dos elementos objetivos da demanda.

Palavras-chave: Causa petendi. Teoria. Processo Civil. Recursos.

\section{THE CAUSA PETENDI BEHAVIOUR IN STRICT LAWS - SHORT NOTES}

SUMMARY: The causa petendi in the Brazil legal system is fundamental in identifying the demand and merit the right of the author of this action. This cause petendi in two doctrinal currents that seek to focus the element to which strives to be prevalent at the expense of another. When viewing the institute procedural here the resources of strict law the character and nature of these resources modify the design of the ordinary object observed, to the invert the substantial of this object but not it essentially. For all restricts this study is the causa petendi, one of the elements of objective demand.

Keywords: Causa petendi. Theory. Due Process of Law. Appeals.

33 Advogado. Inscrito na $70^{\text {a }}$ Subsecção da OABSP. Graduado pela Faculdade de Direito da Universidade de Franca - UNIFRAN. 


\section{INTRODUÇÃO}

A finalidade do texto é a apresentação do comportamento da causa de pedir - causa petendi - nos recursos de estrito direito nas ações singulares, cíveis, onde houver contraditório, com isso, excluídas as vias administrativas (processo de dúvida), reclamação, correição parcial, ou em decisão proferida pelo Presidente de tribunal no processamento de precatório em sede jurisdicional (ADIn n. 1.098-SP), de modo perfunctório e breve.

Não tem o condão de esgotar o assunto, senão o de apresentar de forma concisa este relevante tema.

\section{TEORIA E CONCEITO DE CAUSA DE PEDIR}

A causa de pedir, historicamente, apresenta-se pelo embate de duas teorias, com o fito de estabelecer qual o conteúdo da causa de pedir, a da substanciação e a da individuação.

A primeira apresenta-se a causa de pedir a exposição dos fatos constitutivos do direito afirmado pelo autor; a causa de pedir, mutatis mutandis, seria aquele conjunto de fatos em que o autor se baseia para propor a sua ação.

Já para a segunda, não interessariam aqueles fatos constitutivos em que o autor se basearia para propor a sua ação, mas sim, para a configuração da causa de pedir, a afirmação do autor em qual relação jurídica se fundamenta seu pedido (VIANA, 2002, p. 95).

Cada teoria releva a prevalência do aspecto diverso do fenômeno jurídico, ora uma releva os fatos nascedouros da relação jurídica de onde se irá extrair o pedido; outra, a qualificação jurídica da situação afirmada pelo autor. Bedaque (2002, p. 34) resume:

A teoria da substanciação, coordenada com o princípio da eventualidade, exige a dedução de todos os fatos históricos invocados como constitutivos do direito afirmado. A teoria da individuação exige apenas a especificação do direito substancial, tendo a causa de pedir a função de identificar a relação jurídica controvertida. As duas teorias representam o verso e o reverso da moeda.

O ordenamento jurídico pátrio adota a teoria onde a causa de pedir em que há exposição dos fatos constitutivos do direito afirmando pelo autor, inciso III do art. 282 do 
CPC. Pois, como se nota, esse inciso III exige a narração dos fatos constitutivos. Portanto, causa de pedir próxima (fundamentos jurídicos) e causa de pedir remota (fatos constitutivos), nesse sentido, Moreira (2001, p. 17).

Já, o pedido (objeto) é aquilo que se pede em juízo e que constitui o núcleo da pretensão. O pedido é o objeto da demanda, é o objeto da ação e do processo, é o que o autor pede (SANTOS, 1969, v. 2, p. 100), e, pode ser dividido em: a) pedido imediato é aquilo que imediatamente se pede, e que é a atuação da lei, consistente numa providência jurisdicional (declaratória, condenatória, constitutiva, de execução ou cautelar); b) pedido mediato é o bem ou interesse que se quer ver tutelado pela sentença, seja esse bem material ou imaterial, econômico ou moral. Assim o autor pede que o réu seja condenado (sentença condenatória) a restituir-lhe o imóvel; aquele é o objeto imediato; este, o mediato, leciona Alvim (2005, p. 149).

A causa do pedido - causa petendi -, causa de pedir ou causa da ação é a razão ou o motivo pelo qual se exercita a ação. No ordenamento jurídico pátrio é o próprio fundamento do pedido (ALVIM, 2005, p. 149). Figueira Júnior (2001, v. 4, t. 2, p. 43) diz que a causa de pedir representa o núcleo da petição inicial.

E, neste ponto, Santos (1969, v. 2, p. 101) diz que a causa de pedir (fatos e os fundamentos jurídicos de sua pretensão) deve transparecer as condições da ação - a possibilidade jurídica do pedido, a legitimação para agir, o interesse de agir.

Como ligar pedido e causa de pedir? "Todo pedido tem uma causa. Identificar a causa petendi é responder à pergunta: por que o autor pede tal providência? Ou, em outras palavras: qual o fundamento de sua pretensão?", doutrina Moreira (2001, p 15), e continua:

Constitui-se a causa petendi do fato ou do conjunto de fatos a que o autor atribui a produção do efeito jurídico por ele visado. As mais das vezes, podem distinguir-se um aspecto ativo e um aspecto passivo na causa petendi; por exemplo, se o autor reclama a restituição de quantia emprestada, a causa petendi abrange o empréstimo, fato constitutivo do direito alegado (aspecto ativo), e o não pagamento da dívida no vencimento, fato lesivo do direito alegado (aspecto passivo).

Ora, a causa de pedir, como se extrai da doutrina de Alvim (2000, v. 1, p. 456):

Os fatos contidos na inicial, qualificados como causa petendi, constituem efetivamente o fundamento jurídico da demanda. O autor deve demonstrar que os fatos descritos levam necessariamente à conclusão ou conclusões pedidas, isto é, à relação de causa e efeito 
(no plano lógico e volitivo do autor) entre os fatos jurídicos e o pedido, ou seja, os fatos e suas conseqüências.

Afigura-se-nos que a causa petendi é constituída pelos fatos e a respectiva fundamentação jurídica. São os fatos jurídicos em virtude dos quais nasce o interesse de agir ou mesmo a necessidade de agir, sob pena de ter o autor prejuízo.

O elemento causal faz parte do critério tria eadem ou tríplice identidade (quando se tratar da coisa julgada) e com mais dois aspectos, o pedido e as partes. O processo, como instrumento através do qual a parte exerce o seu direito de agir é relação jurídica e esta não pode subsistir sem que existam sujeitos, daí ter-se afirmado que judicium est actus ad minus trium personarum (FUX, 2004, p. 180).

Cabe ao jurisdicionado trazer ao juiz a situação carente de tutela, e ao magistrado, aplicar a lei (TALAMINI, 2005, p. 71). A causa de pedir é integrada/formada pela causa fática (remota) + causa jurídica (próxima), o processo que se faz para enquadrar chama-se subsunção.

Ressalta a relevância das observações no processo de conhecimento quando todo o procedimento desse é voltado, focado, na investigação dos fatos ocorridos, como pressuposto para a aplicação do direito, o conhecimento dos fatos (alegações de fatos) e, para a satisfação da jurisdição em aplicar o direito aos fatos, merece análise fática do processo (MARINONI; ARENHART, 2000, v. 5, p. 28), não há juízo de mérito, apenas declaratório, é atividade lógica e não material (WAMBIER, 2007, v. 2, p. 42).

De qualquer forma, a descoberta da verdade sempre foi indispensável para o processo. Na realidade, esse é tido como um dos objetivos, senão o principal, do processo. Através do processo (especialmente aquele de conhecimento), o juiz descobre a verdade sobre os fatos, aplicando, então, a esses fatos a norma apropriada. O chamado "juízo de subsunção" nada mais representa do que esta idéia: tomar o fato ocorrido no mundo físico e, a ele, aplicar a regra abstrata e hipotética prevista no ordenamento jurídico. A propósito, Liebman, ao conceituar o termo "julgar", assevera que tal consiste em valorar determinado fato ocorrido no passado, valoração essa feita com base no direito vigente, determinando, como conseqüência, a norma concreta que regerá o caso (MARINONI; ARENHART, 2000, v. 5, p. 29).

Para Engisch (2001, p. 95), sobre a lógica do processo de subsunção:

A um conceito apenas pode ser subsumido um conceito. De conformidade com essa idéia, um trabalho recente sobre a estrutura 
lógica da aplicação do Direito acentua: a subsunção de um caso a um conceito jurídico "representa uma relação entre conceitos: um facto tem de ser pensado em conceitos, pois que de outra forma - como facto - não é conhecido, ao passo que os conceitos jurídicos, como o seu nome o diz, são sempre pensados na forma conceitual". São, portanto, subsumidos conceitos de factos a conceitos jurídicos.

Assim, explica Talamine (2005, p. 72), sobre os elementos integrantes da causa de pedir:

[...] (i) pela descrição dos fatos que servem de fundamento ao pedido e (ii) pela correlação lógico-jurídica entre os fatos descritos e a consequiência jurídica pleiteada. Essas são, respectivamente, a causa fática (ou remota) e a causa jurídica (ou próxima). Incumbe ao autor apenas narrar os fatos relevantes e formular pedido que seja, ao menos em tese, compatível com esses fatos. Não é ônus (perfeito) do autor e, consequentemente, não integra a causa petendi - a descrição do exato caminho jurídico pelo qual, com base naqueles fatos, chega-se àquelas consequiências. Também isso decorre do iura novit curia. Desse modo, não integram a causa de pedir: nem o nomen iuris empregado pelo autor, nem o enquadramento dos fatos em uma específica hipótese de incidência normativa (fattispecie). No curso do processo, o juiz pode rever essa tipificação, desde que se cinja aos limites do fundamento fático e dos efeitos jurídicos pleiteados. Nas mesmas condições, também o autor pode alterar tal enquadramento sem que isso afronte a estabilidade da demanda. Em contrapartida, rejeitado o pedido fundado numa dada causa de pedir, não será tal mudança de enquadramento que permitirá a repropositura da demanda, tal intento esbarrará na coisa julgada.

A causa de pedir está na fundamentação, doutrina Santos (apud ALVIM, 2005, p. 149). A saber, na doutrina, o contencioso instala-se em saber qual o conteúdo da causa de pedir, ou no dizer de Chiovenda "come minimum necessario a identificare la domanda" (apud CAZETTA JÚNIOR, 2002, p. 238).

\section{IDENTIFICAÇÃO DA DEMANDA PELA CAUSA DE PEDIR ${ }^{34}$}

Restringe-se $\mathrm{e}^{35}$ a identificação da demanda a analisar a causa de pedir. E, quando se tenta caracteriza-la mediante a compreensão de seu conteúdo é fundamental, doutrina

\footnotetext{
${ }^{34}$ Para um estudo completo, é necessário analisar o princípio da eventualidade que, em muitos casos, alargará a moldura de atuação do julgador, tendo em vista, v. g., o fenômeno da cumulação de pedidos, etc. Também, deverá ser analisado este princípio-regra com o sistema de preclusões e a rigidez da estabilização da demanda, cf: Dinamarco (1996, p. 75).

35 Sem prejuízo de remeter ao leitor ao estudo da tríplice identidade, ao qual terá a noção exata e precisa da identificação da demanda (partes, objeto e pedido).
} 
Bedaque (2002, p. 25). A identificação da demanda pela causa de pedir é o que se diz dos limites e contornos que o autor quis exatamente para pretender o seu direito. Para Moreira (2001, p. 9):

Chama-se demanda ao ato pelo qual alguém pede ao Estado a prestação de atividade jurisdicional. Pela demanda começa a exercerse o direito de ação e dá-se causa à formação do processo. Só por exceção existe, em nosso direito, processual civil sem demanda que o instaure; é o princípio da iniciativa da parte (ne procedat iudex ex officio; nemo iudex sine actore), consagrado no art. 262.

Através da demanda, formula-se a parte um pedido, cujo teor determina o objeto do litígio e, consequentemente, o âmbito dentro do qual toca ao órgão judicial decidir a lide (art. 128). Ao proferir a sentença de mérito, o juiz acolherá ou rejeitará, no todo ou em parte, o pedido do autor (art. 459, $1^{\text {a }}$ parte). Não poderá conceder providência diferente da pleiteada, nem quantidade superior ou objeto diverso do que se pediu (art. 460); tampouco deixar de pronunciar-se sobre o que quer que conste do pedido. É o princípio da correlação (ou da congruência) entre o pedido e a sentença (ne eat iudex ultra vel extra petita partium), só afastável ante exceção legal expressa.

Dinamarco (2001, v. 1, p. 247) diz:

Não creio que a demanda seja o mérito da causa. Vejo nela, apenas, o veículo de algo externo ao processo e anterior a ele, algo que é trazido ao juiz em busca do remédio que o demandante quer. A demanda é algo estritamente processual, pressuposto processual, é ato formal do processo, que com ele tem vida e nele se exaure. Ela é o veículo da pretensão do demandante, que é uma sua aspiração a determinado bem ou a determinada situação jurídica que, sem o processo e sem a intercessão judicial, o sistema o impede de obter.

E, em outro estudo, Dinamarco (2003, v.2, p. 107) esclarece que:

Assim como demandar equivale a pedir, há situações em que demanda é também sinônimo de pedido. Não o peditum, que é o objeto da pretensão, mas a pretensão em si mesma, como ato de demandar, pedir. Julgar a demanda é, afinal de contas, julgar o pedido que ela contém.

A demanda não se confunde com o mérito, apenas é veículo da pretensão do demandante (RODRIGUES, 2000, v. 1, p. 62), o provimento pretendido por este deve 
corresponder ao chamado princípio da correlação, da congruência ou da adstrição - arts. $128^{36}, 459$ e 460 , ambos do CPC.

Bedaque (2002, p. 24-5) esclarece que à luz desses dispositivos está o juiz, objetivamente limitado aos elementos da demanda deduzidos pelo autor da inicial. O pedido formulado e os motivos deduzidos pelo autor representam o espaço, ou moldura ao qual o julgador deve atuar. Há, aqui, a observação do fenômeno do julgamento ultra ou extra petita, o que impõe ou não a nulidade da sentença.

Há, como salienta Wambier (2007, p. 383), sobre a rescindibilidade, não apenas por violação de lei material, mas por lei processual, e colaciona: STJ, 4a. T., REsp 11.290-AM, rel. Min. Sálvio de Figueiredo Teixeira, j. 04.05.1993, DJU 07.06.1993, p. 11261; TJRS, AR 7.184, rel. Osmar Gomes Nunes, j. 04.04.1975, v. u., RJTJRS 53/186; TJSP, AR 269.425, rel. Cícero Toledo Piza, j. 04.08.1981, v. u., RJTJSP 73/265; TJCE, AR 276, rel. Araújo Lima, j. 15.03.1977, v. u., Jurisp. e Dout. 114/73.

Também, os princípios estão abrangidos pela rescisória. Aliás, Wambier (2007, p. 298) salienta que não pode pinçar "[...] causa petendi diferente daquela eleita pelo autor na formulação da peça inicial.” Clara alusão ao princípio da congruência (petitum/decisum) ${ }^{37} 38$, neste sentido, esse princípio traça os limites de atuação do poder estatal, em apertada síntese,

${ }^{36}$ A este respeito, o art. 128, do CPC, alude ao princípio da inalterabilidade da demanda, estudo de forte impacto na causa de pedir: a sua modificação, cf: Rodrigues (2000, v.1, p. 62-3).

${ }^{37}$ Sobre a mitigação da regra da adstrição da sentença ao pedido: "De qualquer forma, os arts. 84 do CDC e 461 do CPC dão ao juiz o poder de determinar, para a prestação da tutela do direito, forma diversa da solicitada, assim como meio executivo diferente do requerido. Tal possibilidade está expressa nesses artigos, pois eles dão ao juiz o poder de conceder a tutela específica ou o resultado prático equivalente ao do adimplemento, assim como de impor multa e determinar qualquer outra medida executiva necessária, ainda que nenhum ou outro meio de execução tenha sido requerido.

"A ruptura da regra da tipicidade dos meios de execução, isto é, da regra de que o autor e o juiz apenas poderiam se valer dos meios executivos expressamente definidos na lei, não implicou apenas na possibilidade do uso de meio executivo não previamente estabelecido, mas também na mitigação da regra da adstrição da sentença ao pedido.

“[...] Mais precisamente: o autor tem o direito de requerer a forma e a modalidade executiva que lhe pareçam adequadas à tutela do direito - e dessa forma construir a sua ação -, enquanto o juiz tem o poder de, inclusive fugindo do pedido, determinar a forma e meio executivo que sejam necessários à prestação da tutela do direito." (MARINONI, 2006, v. 1, p. 374-5).

${ }^{38}$ Também, sobre o princípio da congruência: "Ao elaborar a petição inicial, o autor formula um pedido que tem como conteúdo o objeto do litígio. Ele pede ao órgão judicial a realização de determinada providência. Nesse momento, ele estabelece os limites do julgamento da demanda. Esse é o princípio da congruência, ou da correlação que é a adstrição do juiz ao pedido. Assim, há uma restrição do juiz de conceder provimento igual ao que foi pleiteado, nem mais, nem menos e nem diferente. Dentro do pedido estão contidos o pedido imediato e o pedido mediato. Aquele é a providência jurisdicional solicitada, já este é o bem da vida que o autor deseja obter.

"Com relação ao tipo de tutela requerida pelo art. 461 do CPC, o pedido imediato irá variar entre a tutela específica e/ou o resultado prático equivalente. Já o pedido mediato irá ser configurado pela obrigação de fazer ou de não fazer, ou seja, 'o que fazer' ou 'o que não fazer'. Ressalta-se que o pedido mediato não sofrerá modificações, pois o provimento jurisdicional deve ser emitido com base nas necessidades do autor, guiado por sua verdadeira vontade (AMIGO, 2007, v. 152, p. 360)”. 
não the sendo lícito: a) conceder bem maior ou estranho ao pedido formulado pela parte; b) furtar-se a decidir o caso que lhe foi apresentado, nos seus exatos termos; e, c) esquivar-se da análise das questões fáticas suscitadas pelas partes, desde que deduzidas no momento apropriado (CATALAN, 2007, v. 147, p. 76). E, leciona Wambier (2007, p. 299-300):

As causae petendi têm a função de identificar o pedido, exatamente da mesma forma que os fundamentos do decisório delimitam o seu sentido. Assim, deve entender-se que a identidade entre objeto do pedido e objeto da sentença envolve também a identidade de causa de pedir (da petição inicial) e de fundamento (da sentença).

A encerrar, a sentença extra petita concede o pedido mas, por outro fundamento que não a causa de pedir invocada pela parte, já decidiu: STJ, 3ª T., REsp 746.622-PB, rel. Min. Nancy Andrighi, j. 26.09.2006, DJ 23.10.2006, p. 309; STJ, 2a. T., REsp 617.109-RS, rel. Min. Castro Meira, j. 26.09.2006, DJ 04.10.2006, p. 207.

Todavia, é importante que se sublinhe que alterar-se o fundamento jurídico da inicial (qualificação jurídica da causa de pedir, e não a sua versão fática) na sentença não a torna extra petita. A subsunção do fato à norma é dever do juiz: pode a sentença, ao julgar ação em que se deu equivocada denominação jurídica ao fato, promover a correta interpretação do direito, o que não gera nulidade de tal ato processual. Trata-se, aliás, de um dever do juiz (WAMBIER, 2007, p. 300).

Também, arestos a corroborar com o posicionamento doutrinário: STJ, 6ª T., REsp 496.814-PE, rel. Min. Hamilton Carvalhido, j. 19.05.2005, DJ 01.07.2005, p. 649; STJ, ${ }^{\mathrm{a}}$. T., REsp 551.959-RS, rel. Min. Luiz Fux, j. 07.04.2005, DJ 06.06.2005, p. 181.

\section{CAUSA DE PEDIR NOS RECURSOS DE ESTRITO DIREITO - SÍNTESE}

Os recursos em comento estão previstos nos arts. 102, III, e 105, III, ambos da CF/88; arts. 541 e ss, do CPC; e, na Lei n. 8.038, de 28 de maio de 1990, arts. 26 usque 29. Sem prejuízo das casuísticas previstas para um ou outro, as petições distintas deverão conter (art. 26): a exposição do fato e do direito (I); a demonstração do cabimento do recurso interposto (II); e, as razões do pedido de reforma da decisão recorrida (III).

Não obstante as peculiaridades de direito ao qual versam cada recurso, o âmbito de sua análise vincula-se ao objeto deste estudo. Mas, antes, é importante ressaltar a função destes recursos. 
Os recursos excepcionais ou de direito estrito, aqui tratado ${ }^{39}$, são aqueles meios de impugnação típicos que irão ser julgados pelo Supremo Tribunal Federal e pelo Superior Tribunal de Justiça, o recurso extraordinário (RE) e o recurso especial (REsp), respectivamente. Esse na justiça comum e eleitoral.

Não é objeto pesquisar sobre a nomenclatura ou enquadramento desses recursos em comento, se são meio de impugnação quanto à sua essencialidade, grau revisional ou segundo a natureza do juízo a quo (MANCUSO, 2007, p. $52^{40}$ ).

Sem embargos, o iter para o conhecimento destes excepcionais: preenchimento, como todos os recursos, dos pressupostos genéricos, objetivos e subjetivos; atendimento no âmbito do interesse de recorrer, da exigibilidade de cuidar-se de causa decidida em única ou última instância; implemento das especificações de base constitucional, ou seja, o cabimento previsto nas alíneas do permissivo (MANCUSO, 2007, p. 239).

\subsection{O COMPORTAMENTO DA CAUSA DE PEDIR NOS RECURSOS DE ESTRITO DIREITO}

As questões postas à análise dos superiores é questão de direito, decorrentes de questão de fato, para ambos os recursos, o fenômeno é análogo. Não pode o tribunal se sujeitar a apreciar por sua iniciativa, os fundamentos da impugnação.

A causa de pedir nos recursos excepcionais, conforme o magistério de Tucci (apud CAZZETA JÚNIOR, 2002, p. 246) deve comportar-se da seguinte forma:

Tem-se escrito que os tribunais superiores apenas conhecem da matéria jurídica bem delineada, não se adequando a eles as regras iura novit curia e da mihi factum, dabo tibi ius, próprias dos juízos monocráticos e colegiados de segundo grau, que conhecem da matéria jurídica e fática. É evidente o equívoco! Aos recursos extraordinário e especial também se aplicam tais regramentos, uma vez que os tribunais superiores não ficam subordinados à iniciativa do recorrente na identificação do permissivo do recurso. Dispensa-se, destarte, a indicação desse dispositivo, mas não daquele do qual emerge a questão constitucional ou a questão federal. E é exatamente por esse motivo que se impõe, à luz da Súmula 282 do Supremo Tribunal Federal, o prequestionamento da questão objeto do recurso.

\footnotetext{
${ }^{39}$ Também há o recurso de revista, âmbito trabalhista, justiça especializada, não objeto deste trabalho.

${ }^{40}$ Cf.: especialmente o item que trata sobre o enquadramento desses recursos dentre os meios de impugnação, do mesmo autor.
} 
Mutatis mutandis, desse fenômeno, o princípio da mihi factum, dabo tibi ius, autoriza o juiz a identificar o direito invocado pelos fatos declinados, e dizer o direito segundo a fattispecie. Nas vias ordinárias - primeiro grau de jurisdição e Tribunais de Justiça -, não vincula ao juízo monocrático ou ao colegiado, podendo esses utilizar fundamentos, ou seja, não há vinculação com o invocado pelas partes. Fenômeno diverso ocorre nos tribunais superiores, há vinculação.

Neste sentido, Carneiro (1999, p. 183).

Como bem referiu o Min. Cláudio Santos, para os recursos constitucionais não vigoram os conhecidos brocardos jura novit curia e da mihi factum, dabo tibi ius: os tribunais superiores "aplicam apenas o direito invocado e somente solucionam o dissídio apontado pelas partes".

Assim, o que consiste o comportamento da causa de pedir nos recursos de estrito direito? A observação das doutrinas e a jurisprudência apontam que a questão de fato que deve ser exposta nas razões dos recursos, são as questões (constitucional ou federal) das quais constituem erros de direito supostamente cometidos por tribunais inferiores, a questão transmuda-se de direito para fato, $v . g$., a pretensão de simples reexame de prova não enseja recurso especial, Súmula 279 do STF e a Súmula 7 do STJ. O objeto de conhecimento é limitado, excluem-se juízos probatórios, justificável esta redução para que a função seja feita por um único tribunal (CAZZETA JÚNIOR, 2002, p. 248).

Não se configura questão federal na análise e apreciação dos fatos tal como estiver sido efetuada no tribunal prolator da decisão impugnada, ventila Carneiro (2005, p. 34). Já decidiu o STJ no Resp 142.616, rel. Min. Barros Monteiro, que “[...] a chamada "valoração da prova', a ensejar recurso especial, é aquela em que há errônea aplicação de um princípio legal ou negativa de vigência de norma pertinente ao direito probatório.” Também, REsp 120.216.

Assim, a interposição de RE contra decisão proferida em ação rescisória tem jurisprudência pacífica do STF no sentido de que o objeto deve ter questões relativas à ação rescisória e não à decisão rescindenda, conforme: $1^{\mathrm{a}}$. T., AGRAG 152.725-DF, rel. Min. Moreira Alves, DJ de 04.04.1997, j. em 28.06.1996; 1 ${ }^{\mathrm{a}}$. T., RE 225.469-SE, rel. Min. Moreira Alves, DJ de 31.03.2000, j. em 22.02.2000; 1ª T., AGRRE 118.317-BA, rel. Min. Celso de Mello, DJ de 22.09.1995, j. em 08.03.1994; 1ª T., RE 118.116-RS, rel. Min. Octávio Gallotti, DJ de 23.02.1996, j. em 31.10.1995; 1 a . T., RE 150.055, rel. Min. Ilmar Galvão, DJ de 12.09.1997, j. em 29.04.1997. 
Silva (2003, p. 135-6) alude a possibilidade de coincidir a causa de pedir da ação rescisória com a causa de pedir do RE, seja a violação de dispositivo constitucional, bem como essa questão seja a razão de decidir do acórdão que julgar a rescisória, que legitimaria o cabimento da interposição do RE por violar esse dispositivo constitucional - no RE 163.566PB, rel. Min. Sydney Sanches, DJ de 29.03.1996, j. em 27.02.1996.

Por outro lado, a necessária observação à própria finalidade dos recursos que tem por objetivo; " [...] resguardar o sistema jurídico e não a situação individual das partes, a não ser imediatamente ou de modo indireto", e, "[...] se sua finalidade é a de resguardar o direito objetivo, é natural que sejam cabíveis tais recursos, de um modo geral, na medida em que seu resultado seja transcendente à situação das partes, desempenhando função paradigmática ou exemplificadora” (WAMBIER, 2001, p. 145).

Daí dizer que a própria função dos recursos, que é eminente pública, e que tem característica primordial a guarda, controle, preocupação, em defender a lei - nomofilaxia. Imediatamente atinge a República, e mediatamente o jurisdicionado. A finalidade do recurso visa a correção da decisão no interesse da parte; a prevalência e uniformidade de aplicação da lei, "[...] não é uma via meramente consultiva, nem um palco de desfile de teses meramente acadêmicas" (CARNEIRO, 2007, v. 143, p. 205), em comentário ao REsp 660.519-CE, $1^{\text {a }}$ T., rel. Min. Teori Albino Zavascki, j. 20.10.2005, DJ 07.11.2005, v.u.

O Supremo relata matéria de fato, mas não julga. A missão consiste em verificar se houve erro de direito, quer in iudicando, quer in procedendo, porque de erro de fato não se cogita mais.

\section{CONCLUSÃO}

Creia-se que a finalidade para expor o comportamento da causa de pedir nos recursos de estrito direito, foi alcançada, e não esgotada.

Importante salientar é que o comportamento da causa de pedir, quando da identificação da demanda, tem como finalidade possibilitar ao juízo monocrático ou no colegiado (Tribunais de Justiça) atuar sobre uma determinada moldura normativa, operandose os princípios da mihi factum, dabo tibi ius e o iura novit curia; nos tribunais superiores, diversamente, terá que conhecer a questão de direito, ou o erro de operação efetivamente praticado pelo inferior. 
O modelo comportamental da causa de pedir no âmbito de apreciação dos recursos de estrito direito é a mutação da questão apresentada no veículo para se obter a pretensão de mérito.

Desta forma, a causa de pedir não se harmoniza com a estrutura do RE, nem com a função que ele preordena, diversa da que é reservada à demanda, já concluída.

Assim, a causa de pedir nos excepcionais, tem característica horizontal, sendo o mérito e admissibilidade invertida; tem o escopo de impugnar o critério adotado pelo órgão a quo, e demonstrar em que momento houve violação ao texto constitucional ou federal - aqui, a questão primordial.

\section{REFERÊNCIA}

ALVIM, A. Manual de direito processual civil. 7. ed. São Paulo: Revista dos Tribunais, 2000. v. 1.

ALVIM, J. E. C. Teoria geral do processo. 10. ed. Rio de Janeiro: Forense, 2005.

AMIGO, B. N. A natureza jurídica do resultado prático equivalente. REVISTA DE PROCESSO - REPRO. Ano 32, n. 152, out./2007.

BEDAQUE, J. R. dos S. Os elementos da demanda examinados à luz do contraditório. TUCCI, J. R. C. e; ______ (Coord.). Causa de pedir e pedido no processo civil: questões polêmicas. São Paulo: Revista dos Tribunais, 2002.

CARNEIRO, A. G. Requisitos específicos de admissibilidade do recurso especial. STJ: Dez Anos a Serviço da Justiça: Doutrina. Ed. Comemorativa. Brasília: Superior Tribunal de Justiça, 1999. v. 6.

Recurso especial, agravos e agravo interno. 4. ed. Rio de Janeiro: Forense, 2005.

CARNEIRO, T. A. Recurso especial, efeito translativo. Matéria de ordem pública. REVISTA DE PROCESSO - REPRO. Ano 32, n. 143, jan./2007.

CATALAN, M. J. O princípio da congruência e o acesso à ordem jurídica justa: reflexões sobre o tema da legalidade constitucional. REVISTA DE PROCESSO - REPRO. Ano 32, n. 147 , mai./2007.

CAZETTA JÚNIOR, J. J. Conteúdo da causa de pedir e proposta de aplicação dessa categoria ao recurso extraordinário: um exame crítico. TUCCI, J. R. C. e; BEDAQUE, J. R. dos S. (Coord.). Causa de pedir e pedido no processo civil: questões polêmicas. São Paulo: Revista dos Tribunais, 2002. 
DINAMARCO, C. R. A reforma do Código de Processo Civil. 3. ed. São Paulo: Malheiros, 1996.

Fundamentos do processo civil moderno. 4. ed. São Paulo: 2001. v. 1.

Instituições de direito processual civil. 3. ed. São Paulo: Malheiros, 2003. v. 2.

ENGISCH, K. Introdução ao pensamento jurídico. Tradução de J. Baptista Machado. 8. ed. Lisboa: Fundação Calouste Gulberkian, 2001.

FIGUEIRA JR, J. D. Comentários ao Código de Processo Civil: do processo de conhecimento, arts. 282 a 331. Coord. de Ovídio A. Baptista da Silva. São Paulo: Revista dos Tribunais, 2001. v. 4. t. 2.

FUX, L. Curso de direito processual civil. 2. ed. Rio de Janeiro: Forense, 2004.

MANCUSO, R. de C. Recurso extraordinário e recurso especial. 10. ed. São Paulo: Revista dos Tribunais, 2007.

MARINONI, L. G; AREnHART, S. C. Comentários ao Código de Processo Civil: do processo de conhecimento. São Paulo: Revista dos Tribunais, 2000. v. 5.

MARINONI, L. G. Curso de processo civil: teoria geral do processo. São Paulo: Revista dos Tribunais, 2006. v. 1.

MOREIRA, J. C. B. O novo processo civil brasileiro: exposição sistemática do procedimento. 21. ed. Rio de Janeiro: Forense, 2001.

RODRIGUES, M. A. Elementos de direito processual civil. 2. ed. São Paulo: Revista dos Tribunais, 2000. v. 1.

SILVA, B. M. Prequestionamento, recurso especial e recurso extraordinário. 2. ed. Rio de Janeiro: Forense, 2003.

TALAMINI, E. Coisa julgada e sua revisão. São Paulo: Revista dos Tribunais, 2005.

VIANA, Juvêncio Vasconcelos. A causa de pedir nas ações de execução. In: TUCCI, José Rogério Cruz e; BEDAQUE, José Roberto dos Santos. (Coord.). Causa de pedir e pedido no processo civil: questões polêmicas. São Paulo: Revista dos Tribunais, 2002.

WAMBIER, T. A. A. O controle das decisões judiciais por meio de recursos de estrito direito e de ação rescisória: recurso especial, recurso extraordinário e ação rescisória: o que é uma decisão contrária à lei? São Paulo: Revista dos Tribunais, 2001.

$\overline{2007}$.

Nulidades do processo e da sentença. 6. ed. São Paulo: Revista dos Tribunais,

WAMBIER, L. R. (Coord.). Curso Avançado de processo civil: execução. 9. ed. São Paulo: Revista dos Tribunais, 2007. v. 2. 
78

Nucleus, v.5, n.2, out. 2008 